\title{
ORTODOXIA CRISTIANA Y APOLOGIAS ESOTERICAS EN LA ESPAÑA DE CARLOS V. ANILLOS, MAGIA ASTRAL Y MAGIA NATURAL EN LA SILVA DE VARIA LECCION DE PEDRO MEXÍA (1540)*
}

\author{
CHRISTIAN ORTHODOXY AND ESOTERIC APOLOGIES IN THE SPAIN OF \\ CARLOS V. RINGS, ASTRAL MAGIC AND NATURAL MAGIC IN \\ SILVA DE VARIA LECCION OF PEDRO MEXÍA (1540)
}

\author{
ORTODOXIA CRISTÃ E APOLOGIAS ESOTÉRICAS NA ESPANHA DE \\ CARLOS V. ANÉIS, MAGIA ASTRAL E MAGIA NATURAL EM \\ LA SILVA DE VARIA LECCION DE PEDRO MEXÍA (1540)
}

\author{
JUAN BUBELLO \\ Universidad de Buenos Aires - Universidad Nacional de La Plata** \\ https://doi.org/10.46553/EHE.23.2.2021.p140-158
}

\begin{abstract}
Resumen
El abordaje del esoterismo español en el período temprano-moderno continúa siendo notablemente marginal entre los especialistas. En el cruce de la historia cultural y la historia política, investigamos tanto las características de las prácticas y representaciones esotéricas en la España del siglo XVI como las luchas de representación entre los discursos hostiles de los eruditos cristiano-ortodoxos y los apologéticos de los esoteristas. Abordamos la "Silva de varia lección" (1540) de Pedro Mexía (que llegaría a ser designado en 1548 Cronista imperial de Carlos V) para focalizar tanto en las peculiaridades de su representación de anillos mágico-astrológicos como en las características de su discurso apologético frente a la impugnación de la ortodoxia cristiana.
\end{abstract}

Palabras claves

Anillos, magia astral, magia natural, Pedro Mexía, esoterismo.

\begin{abstract}
The approach to Spanish esotericism in the early-modern period continues to be notably marginal among specialists. At the crossroads of cultural history and political history, we investigate both the characteristics of esoteric practices and representations in 16th century Spain and the representational struggles between the hostile discourses of Christian orthodoxy and the apologetics of esotericists. We approach the "Silva de varia lección" (1540) by Pedro Mexía (who was to be appointed in 1548 Imperial Chronicler of Carlos V) to focus both on the peculiarities of his specific representation of magic-astrological rings and on the characteristics of his apologetic speech regarding the criticism of Christian orthodoxy.
\end{abstract}

* Fecha de recepción: 10/09/2020. Fecha de aceptación: 16/03/2021.

** Doctor en Historia y docente categorizado, ORCID: https://orcid.org/0000-0003-1204-6236. Facultad de Filosofía y Letras, Universidad de Buenos Aires - Facultad de Humanidades y Ciencias de la Educación, Universidad Nacional de La Plata. Puan 480, $3^{\circ}$ piso, C1406CQJ, CABA, Argentina, j_bubello@yahoo.com.ar 


\section{Key Words}

Rings, astral magic, natural magic, Pedro Mexía, esotericism.

\section{Resumo}

A abordagem do esoterismo espanhol no inicio da era moderna continua a ser notavelmente marginal entre os especialistas. No cruzamento da história cultural e da história política, investigamos tanto as características das práticas e representações esotéricas na Espanha do século XVI quanto as lutas representacionais entre os discursos hostis de ortodoxia cristã e a apologética dos esotéricos. Abordamos o estudo de la "Silva de varia lección" (1540) de Pedro Mexía (que seria nomeado em 1548 Cronista Imperial de Carlos V) para enfocar tanto as peculiaridades de sua representação específica dos anéis mágico-astrológicos quanto as características de seu discurso apologético em face do desafio da ortodoxia cristã.

\section{Palavras-chave}

Anéis, magia astral, magia natural, Pedro Mexía, esoterismo.

\section{Introducción}

Fue “(...) llamado el Astrólogo como Aristóteles el Filósofo. Con este conocimiento predixo muchas cosas, i su mesma muerte, 20 años antes (...)"2 escribió su biógrafo Francisco Pacheco respecto de Pedro Mexía (1497-1551)3. El propio Mexía en su "Silva de varia lección" (1540), ${ }^{4}$ señaló que ejercía la astrología y que tenía "experiencia" tanto en el "arte mágica natural" como en las "(...) propiedades secretas de cosas (...) [que] son inflyuidas por las estrellas delcielo." 5

Considerando a Mexía un agente cultural de las corrientes esotéricas del siglo XVI ${ }^{6}$ y tras publicar un estado de la cuestión crítico sobre su "Silva"; ${ }^{7}$ continuamos investigando la

\footnotetext{
${ }^{2}$ CASTRO, 2004, 15.

${ }^{3}$ Mexía estudió leyes y se formó en latín y griego, matemáticas e historia. En 1537 y 1538 , adquirió los cargos de cosmógrafo de la Casa de Contratación de la ciudad y alcalde de la Santa Hermandad. En 1548, Carlos V lo designó cronista oficial del Imperio.

${ }^{4}$ Después de la primera edición de la "Silva" (Sevilla, 1540), hubo, en el siglo siguiente otras 32 en castellano (29 completas y 3 parciales) y 75 en lenguas extranjeras (31 francesas, 30 italianas, 5 inglesas, 5 holandesas y 4 germanas). A fines de 1540, Mexía corrigió y aumentó en 10 capítulos su edición prínceps. En 1550, amplió otra vez su texto con 22 capítulos, publicándolo en Valladolid. Aquí utilizamos la edición, basada en la de 1550, de Antonio Castro Díaz (1989).

${ }^{5}$ Mexía lo expresó en tres referencias específicas: "Grandes questiones y contiendas ha avido entre los hombres doctos, antiguos y modernos, sobre la astrología que llamamos judiciaria... en el estudio desta astrología y de la que tracta de los movimientos y cursos de los cielos, que llamamos astronomía, he gastado harto tiempo..." ("Silva”, II, 432); “...son grandes las virtudes de las piedras, según por los libros y por la experiencia tenemos conoscido... la verdad es que estas mayores cosas creen y prometen los que tractaron de los anillos por arte mágica natural hechos... también los que se fabrican por reglas y orden de astrología guardados los tiempos y forma que en ello ponen los auctores..." ("Silva", IV, 2, 317) "De manera que estas propriedades secretas de cosas, que no les vienen de los elementos son influydas por las estrellas del cielo, son de tener en mucho y no burlas dellas, pues tan grandes hombres las escriven, y la experiencia nos la muestra..." ("Silva”, I, 815).

${ }^{6}$ Sin perjuicio de los debates teóricos desarrollados, que conocemos pero no detallaremos por motivos de espacio, en cuanto a la categoría de "esoterismo occidental", remitimos a Faivre (FAIVRE, 1992; FAIVRE, 1994).

${ }^{7}$ BUBELLO, 2019, 311-319.
} 
historia del esoterismo en la España del Siglo de Oro ${ }^{8}$ pues, como se verifica al repasar el Dictionary of Gnosis and Western Esotericism ${ }^{9}$ y los trabajos especializados de las últimas dos décadas -que excluyen a los españoles o los abordan tangencialmente-, el caso español sigue siendo marginal en nuestro campo de estudios sobre el "esoterismo occidental". Volvemos entonces a la "Silva" desde la historia cultural ${ }^{10}$ y con ineludibles previsiones metodológicas, ${ }^{11}$ para analizar las prácticas y representaciones mágico-astrales y mágiconaturales con anillos y, paralelamente, el discurso apologético con el cual Mexía pugnó con las representaciones hostiles sostenidas al respecto por la ortodoxia cristiana.

\section{Anillos, magia astral, magia natural, ortodoxia cristiana y Mexía}

Mexía escribe que ciertos anillos (o sortijas), portando piedras de diversa clase grabadas con imágenes, adquieren un poder procedente "de los planetas y estrellas":

"De la virtud y provecho de los anillos hechos por regla de astrología (guardados a ciertas horas y tiempos, y considerando los miramientos y cursos de las estrellas, assí en la fábrica del mismo anillo, como en la escultura de la piedra dél de ymágines particulares y señaladas) (...) muchos auctores lo tractan, diciendo adquirir la piedra nueva virtud y fuerça, allende de la natural suya, por la influencia de los planetas y estrellas al tiempo que se esculpió la imagen, y por la liga y compañía de tal piedra y ymagen con tal metal en quien particularmente influyen (...) para esforçar y acrescentar las virtudes y fuerças naturales, y para otras grandes utilidades y efectos (...)."12

En nuestro campo, compartimos un criterio para distinguir amuletos respecto de los talismanes: los primeros son objetos naturales -sin imágenes- usados en alguna parte del cuerpo; los últimos son producidos por el hombre, generalmente grabados con imágenes de planetas, signos del zodíaco, etc. ${ }^{13}$ Mexía se está refiriendo pues a los anillos que, en tanto talismanes portadores de imágenes grabadas en piedras o gemas, quedaban conectados a las influencias de "los planetas y estrellas" y que, por ende, otorgaban "efectos". ${ }^{14}$

Ese párrafo remite a las representaciones de magia astral, un dominio específico de las prácticas mágicas eruditas de la Europa de su época, ${ }^{15}$ que fueron observadas en el $D e$ occultis et maizifestis sive Liber intelligentiarum de Antonio da Montolmo (circa 1360-

\footnotetext{
${ }^{8}$ BUBELLO, 2017, 199-211; BUBELLO, 2017b, 551-581; BUBELLO, 2016, 95-117; BUBELLO, 2015, 79103; BUBELLO, 2014, 189-197; BUBELLO, 2013, 169-179; BUBELLO, 2012, 1-24; BUBELLO, 2010.

${ }^{9}$ HANEGRAAFF, et al., 2005.

${ }^{10}$ CHARTIER, 1992, 45-63.

${ }^{11}$ BUBELLO, 2020, 219-240; BUBELLO, 2005, 73-104.

${ }^{12}$ MEXÍA, 1989 (1540), IV, 2, 321-322

${ }^{13}$ FORSHAW, 2018, 16; HANEGRAAFF, et al., 2005, 66 у p. 519.

${ }^{14}$ Mexía no está haciendo referencia a esa otra práctica talismánica con anillos consistente en inscribirles palabras mágicas específicas (usual en los siglos XIV-XVI). Uno de los ejemplos era la palabra "ananizaptus" (o "ananizapta") para prevenir plagas, epilepsia, demonios; expresión que podría estar asociada a "San Antonio" -el célebre ermitaño que, según la tradición de los primeros cristianos, resistió las tentaciones demoníacas en el Desierto- o, quizás, remita a la fórmula mágica medieval "Antidotum Nazareni auferat necem intoxicationis; Sanctificet alimenta poculaque trinitas alma”. Ver SKEMER, 2006, 155, cita 79.

${ }^{15}$ FORSHAW, 2015, 40-41.
} 
$1394)^{16}$ y en el capítulo "De virtutibus et usu stellarum fixarum" del De Vita Coelitus Comparanda (1489) ${ }^{17}$ de Marsilio Ficino (1433-1499), ${ }^{18}$ entre otros ejemplos.

Ahora, también Mexía afirma que si los anillos portaban ciertas piedras preciosas y gemas, podían ser destinados a múltiples fines pues adquirían "virtud y propiedad natural":

"El anillo con la piedra diamante afirman que aprovecha contra los hechizos; y que, por virtud y propiedad natural, anima y esfuerça el coraçón, señaladamente contra los pantasmas, trasgos o duendes, y ayuda a las mugeres preñadas (...) Y, con la piedra llamada amatista, es bueno para contra ponçoña y evitar la embriaguez (...) La sortija en que se trayga balax, reprime los movimientos de la carne a deshonestidad, ayuda a la salud corporal. Y, si fuere la piedra arbúncol o rubí, tiene fuerça contra el ayre corrupto y venenoso, y también contra los estímulos de la carne y contra las imaginaciones y tristezas. Y el anillo de coral tiene también excelentes effectos, porque mitiga el fluxo de sangre y deffiende de las sombras y espantos de los sueños; aún dizen que alegra el coraçón. Y la de cristal tienen por buena contra los que aojan, y aun para no soñar malos sueños y pesados (...) Y la sortija con la esmeralda affirman que ayuda a guardar castidad ya mitigar los estímulos de la carne; y aún affirman algunos que, si la tiene alguna muger que pierde su virginidad, se quiebra la piedra; y tiene assi mismo, propiedad contra el demonio y las tempestades (...)"19

Mexía aquí remite a representaciones relacionadas con la magia natural (otro de los dominios típicos de las prácticas mágicas eruditas de la Europa de su época). ${ }^{20}$ Describe que esta práctica de portar anillos con piedras, generaba protección contra daños mágicos (hechiceriles y demoníacos), curaba diversas dolencias del cuerpo y emociones, prevenía contra impulsos sexuales instintivos, facilitaba el dormir, el descanso y el sueño, permitía identificar la virginidad en una mujer y protegía contra tempestades.

A estos anillos (sean usados como amuletos o talismanes, portadores de imágenes o piedras y gemas) se les atribuían otras múltiples virtudes mágicas (naturales o astrales). Podían ser usados para afectar la memoria humana -representación construida por el teólogo Petrus Comestor (?-1180) cuando complementó a Flavio Josefo (circa 37-100) para sugerir que Moisés había sido astrólogo- ${ }^{21}$ comprender el lenguaje de los animales -como, en el

\footnotetext{
${ }^{16}$ WEILL-PAROT, 2002, 179-180.

${ }^{17}$ Ver COPENHAVER, 1984, 523-554; COPENHAVER, 1986, 351-369.

${ }^{18}$ Ficino escribió que, para capturar el poder de una estrella, fue aconsejado adquirir su correspondiente hierba y piedra, confeccionar un anillo de oro o plata e insertarle dicha piedra (con la hierba debajo) para usarlo luego en contacto con la carne. Sin embargo, tomando distancia, se inclinaba por juntar ambas en una medicina (más que en un anillo) y usarla observando el momento horario propicio ("Thebit philosophus docet ad captandam alicuius stellae modo dictae virtutem lapidem eius accipere herbamque eiusdem, anulumque aureum facere vel argenteum, in quo lapillum inseras herba subiecta gerasque tangentem... Ego vero quae ad eiusmodi stellas attinent in formam potius medicinae quam anuli componerem, intrinsecus vel extrinsecus adhibendae, opportunitate videlicet praedicti temporis observata.") -extraído de Marsilio Ficino, De Vita Coelitus Comparanda, 1489, ed. KASKE y CLARK p. 278)

${ }^{19}$ MEXÍA, 1989 (1540), IV, 2, 318-319.

${ }^{20}$ FORSHAW, 2015, 39-40.

${ }^{21}$ Josefo había escrito en Antiquitates iudaicae (II, 10-11) que Moisés, al mando del ejército de Egipto para tomar la ciudad real de Saba, prometió matrimonio a Tharbis, la hija del rey. Pero, tras obtener la victoria gracias a la traición de la princesa, regresó a Egipto. En este punto, Comestor añadió en Historia Scholastica (1173), que Moisés, habiendo quedado en obligación de respetar su juramento, para salir de la situación confeccionó astrológicamente dos anillos, uno para la memoria, otro para el olvido -guardando para sí el primero y entregando el otro a Tharbis, por lo que pudo regresar a Egipto dejando a la mujer, que ahora le había olvidado ("Proinde Moyses tamquam vir peritus astrorum duas imagines sculpsit in gemmis hujus efficaciae, ut altera
} 
ámbito literario, exaltó Geoffrey Chaucer (1343-1400) en "The Squire's Tale" de sus Canterbury Tales (circa 1400); ${ }^{22}$ adquirir inteligencia -como apuntó el médico y astrólogo Jerónimo Torrella (circa 1456-1500) cuando refirió la historia del rey Larus de Frigia en su Opus praeclarum de imaginibus astrologicis (Valencia, 1496) ${ }^{23}$ y detectar venenos (como se atribuyó al anillo que, en 1408, poseía el duque de Borgoña). ${ }^{24}$

Mexía parece sugerir que conoce estos u otros relatos similares, pues advierte que en “(...) quanto a las propiedades y virtudes naturales de las piedras (...) querer hazer memoria de todos ellos sería para nunca acabar (...)." ${ }^{25}$ Pero, sin perjuicio de ello, es claro que los ejemplos que aporta en su "Silva" son compatibles con las prácticas y representaciones vigentes dentro y fuera de la península ibérica sostenidas por otros esoteristas (entre otros, Torrella y Ficino) y que, sobre todo, en su voz el uso de esos anillos mágico-astrológicos adquiría un significado positivo.

Ahora, un segundo problema debemos abordar. Pues, en el contexto cultural donde se instala nuestra fuente primaria, estos objetos materiales y culturales que se describen en la "Silva" hacía siglos que asumían un sentido negativo para la ortodoxia cristiana.

En el marco de su disputa contra la "magia" -proceso complejo iniciado en la tardoantigüedad, ${ }^{26}$ las voces cristiano-ortodoxas asociaron una y otra vez a los anillos mágicos con representaciones hostiles, que son susceptibles de ser agrupadas, en la larga duración, con dos entramados de enunciación-descalificación particulares: lo "pagano-supersticioso" (siglos V al XI) y lo "herético-demoníaco" (siglos XI al XVI).

La primera asociación aparece con nitidez cuando Agustín de Hipona (354-430) tildó de práctica "supersticiosa" de los paganos el portar anillos mágicos hechos con huesos de avestruz (De doctrina Christiana II, 20). ${ }^{27}$ La segunda se construyó con la voz de Tomás de

memoriam, altera oblivionem conferret. Cumque paribus annulis eas inseruisset, alterum, scilicet oblivionis annulum, uxori praebuit; alterum ipse tulit, ut sic pari amore, sic paribus annulis insignirentur. Coepit ergo mulier amoris viri oblivisci, et tandem libere in Aegyptum regressus.") -extraído de Pedro Comestor, "Historia Scholástica" (en MIGNE, 1855, 1144). Esta historia sobre el anillo mágico de Moisés circuló entre los astrólogos medievales. Por ejemplo, el inglés John of Eshenden (Johannes Eschuid), en Summa astrologiae judicialis (circa 1347-1348) remitiendo a Comestor, escribe: "Narrat enim magister Exodi capitulo de uxore: Moysi aethyopissa quod Moyses qui sequebatur Ethyopes et fugiebant in civitatem regiam Sabba cumque Carib, filia regis Ethyopum iniecisset oculos in eum ex eo ducto tradidit ei civitatem si duceret eam in uxorem, et ita factum est. Cum autem rediret in Aegyptum non acquievit uxor, inde Moyses tanquam vir peritus astrorum duas imagines sculpsit in gemmis huius modi efficaciae ut altera memoriam altera oblivionem conferret. Cumque pluribus annis conservasset eas annulum oblivionis tradidit uxori; alium annulum secum tulit .Cepit igitur mulier amorem viri oblivisciet ipse Moyses libere in Aegyptum regressus est". (Ver Johannes Eschuid, Summa astrologie iudicialis, Venetiis: Francisci Bolani, 1489: I.1, f. 1ra.).

${ }^{22}$ Chaucer relató la historia del rey Cambuskan, cuya hija, Canacee, recibe un anillo mágico que le permitía comprender el lenguaje de las aves (más tarde entablará una conversación con un halcón herido quien le relata la causa de su estado y entonces ella lo cura). En cuanto a los análisis sobre las aristas mágicas en este poema, remitimos a: LIONARONS, 1993, 377-386; CLOUSTON, 1888-1890.

${ }^{23}$ Larus de Frigia se caracterizaba por su poca inteligencia e incapacidad de dar buen consejo, por lo que se le confeccionó un anillo, de oro puro, en el que se había encerrado un diamante en el momento que Saturno estaba en conjunción con Júpiter en el signo de Aries (y, al llevarlo, se transformó en hombre inteligente y buen consejo). Ver WEILL PAROT, 2007, 145-172.

${ }^{24}$ KIECKHEFER, 2014, 102.

${ }^{25}$ MEXÍA, 1989 (1540), IV, 2, 319-320.

${ }^{26}$ Ver COLLINS, 2019, 461-475; BAILEY, 2001, 963-966; FLINT, 1999, 277-348; BURUCUA, 2001, 479542; KIECKHEFER, 2014, 37; DE MARTINO, 1965, 229-232.

${ }^{27}$ Escribe Agustín de Hipona: “... vel ad consultationes et pacta quaedam significationum cum daemonibus placita atque foederatam, qualia sunt molimina magicarum artium, quae quidem commemorare potius quam 
Aquino (1225-1274) quien, en el marco de su creación de la noción de pacto tácito con el demonio en Summa Theologiae (1265-1274), ${ }^{28}$ vinculó -en Quaestio disputata de anima (1266-1267)- a las "artes mágicas" con el acto de seducir demonios para que permanezcan en "...anillos, las imágenes, o cosas"29 y se completó con el Papa Juan XXII (1244-1334), quien en su bula Super illius specula (1326), asociando magia y herejía, ${ }^{30}$ relacionó el uso de “annulum” con fines mágicos a lo demoníaco y lo herético. ${ }^{31}$

Este segundo horizonte cultural de significado hostil contra los anillos es el que más nos importa, pues se advierte en los discursos ortodoxos difundidos por la península ibérica en los tiempos de Carlos V (1500-1558) en que vivió Mexía sus días y cuyos antecedentes históricos remiten a las dos centurias precedentes a la "Silva".

El dominico catalán e inquisidor de Aragón, Nicolau Eimeric (1320-1399), en su Directorium Inquisitorum (circa 1376) -texto reeditado y corregido por Francisco Peña (1540-1612)- recordó la prohibición de encerrar "al diablo en un anillo". ${ }^{32} \mathrm{El}$ arzobispo e inquisidor de Sevilla, Alonso Manrique de Lara y Solís (1471-1528) alentó a los "buenos cristianos" a denunciar quien posea "...espejos mágicos, anillos mágicos... realice conjuros, haga pactos con el demonio...".33 Incluso, apenas dos años antes de la "Silva", el teólogo aragonés Pedro Ciruelo (1470-1548) en su Reprobación de las supersticiones y hechizerías

docere assolent poetae. Ex quo genere sunt, sed quasi licentiore vanitate, aruspicum at augurum libri. Ad hoc genus pertinet omnes etiam ligaturae atque remedia, quae medicorum quoque disciplina condemnat, sive in praecantationibus, sive in quibusdam notis quos characteres vocantm, sive in quibusque rebus suspendendis atque illigandis, vel etiam aptandis qu odammodo, non ad temperationem corporum, sed ad quasdam significationes aut occultas, aut etiam manifestas; quae mitiore nomine physica vocant, ut quasi non superstitione implicare, sed natura prodesse videantur: sicut inaures in summo aurium singularum, aut de struthionum ossibus ansulae in digitis, aut cum tibi dicitur singultienti ut dextera manu sinistrum pollicem teneas" (AGUSTÍN de HIPONA, 1965, 151-152).

${ }^{28}$ El pacto expreso es aquel en el cual se implora explícitamente la colaboración del demonio, aquel en el cual los hombres invocan la presencia de los espíritus malignos para interrogarlos y solicitar de ellos algún beneficio concreto. El pacto tácito, en cambio, es aquel por el cual los hombres no poseen intención expresa de invocar la ayuda de los ángeles caídos, pero llevan adelante prácticas que pueden impulsar a los demonios a intervenir secretamente. Ver CAMPAGNE, 2002, 69 y ss.

${ }^{29}$ Refiere Tomás de Aquino en su Quaestio disputata de anima (a. 21 co.): "Quod autem aliqua spiritualis substantia alicui corpori obligetur, non est ex virtute corporis potentis substantiam incorpoream detinere; sed ex virtute alicuius superioris substantiae alligantis spiritualem substantiam tali corpori. Sicut etiam per artes magicas, permissione divina, virtute superiorum Daemonum aliqui spiritus rebus aliquibus alligantur, vel anulis, vel imaginibus, vel huiusmodi rebus. Et per hunc modum animae et Daemones alligantur, virtute divina, in sui poenam, corporeo igni." (extraído de MENDOZA, 2016, 163, n. 43).

${ }^{30}$ Ver BOUREAU, 2014, 8-43; BAILEY, 2007, 110-125; PETERS, 1992, 132.

${ }^{31}$ Se escribe en la bula: “... dolenter advertimus, quod etiam cum nostrorum turbatione viscerum cogitamus, quam plures esse solo nomine Christianos, qui relicto primo veritatis lumine, tanta erroris caligine obnubilantur, quod cum morte foedus ineunt, et pactum faciunt cum inferno: damonibus namque immolant, hos adorant; fabricant, ac fabricari procurant imagines; annulum vel speculum, vel phialam, vel rem quamcunque aliam magice ad damones inibi alligandos ab his petunt, responsa ab his recipiunt, et pro implendis pravis suis desideriis auxilia postulant, pro re foetidissima foetidam exhibet servitutem (proh dolor) huiusmodi morbus pestifer, nunc per mundum solito amplius convalescens, successive gravius." (extraído de HILL, 2019, 230232).

${ }^{32}$ Advierte Eimeric: "Tampoco hay que encerrar demonios en un frasco si se desea librarse del brazo secular. San Agustín, Luis Vives y otros se han expresado muy claramente al respecto. ¿Acaso no leemos: 'No encerrarás al diablo en un anillo, ni en un espejo, ni en un frasco ni en ningún otro lugar para arrancarle una respuesta a tu gusto pues los muy poderosos espíritus del mal serían inútilmente forzados por pacto alguno con el hombre a entrar en frascos y permanecer encerrados?" (extraído de PEÑA, 1983, 84).

${ }^{33}$ Citado en PAVIA, 1959, 26-27. 
(1538), relacionó el uso de piedras en anillos con una de las prácticas nigrománticas para llamar "al diablo".34

Esta red de voces ortodoxas hostiles, previas y contemporáneas a Mexía (y también posteriores a su muerte), ${ }^{35}$ generaron condiciones culturales de posibilidad para perseguir a quien emplease anillos con fines mágicos (y otros objetos de igual universo simbólico que no abordaremos aquí). ${ }^{36}$ Cuando el presbítero Joan Vicente fue procesado por la Inquisición de Zaragoza en $1511,{ }^{37}$ los inquisidores precisaron haber encontrado entre sus pertenencias “...un anillo de Salomón para dominar espíritus." 38

Por ende, al observar el marco cultural vigente cuando Mexía escribe, se vislumbra un choque de representaciones en torno a estos anillos: para nuestro mago y astrólogo adquirían un significado positivo pues podían prevenir adversidades y resolver problemas cotidianos; para los agentes de la ortodoxia, recibían uno negativo, porque su utilización implicaba un llamado al diablo, un vínculo a demonios, dominio de espíritus o un pacto con el demonio. Y este conflicto cultural tenía su correlato en el plano político: las autoridades que resguardaban la posición ortodoxa perseguían y eventualmente procesaban a quienes usaban esta clase de anillos.

Ahora, ¿cuál fue la táctica discursiva desplegada en la "Silva" para contrarrestar esas representaciones hostiles y persecuciones? En líneas generales, Mexía no confrontó las voces ortodoxas, pero efectuó ciertas apropiaciones -como veremos- de los Antiguos y de dos contemporáneos, a fin de erigir un discurso apologético en torno a los anillos mágicoastrológicos. Construyó su red de autoridades, que iniciaba con Platón y se extendía hasta su presente, amalgamando en una unidad de sentido a diversas tradiciones culturales. ${ }^{39}$

Explicitando una postura dubitativa sobre el relato que citará, Mexía alude primero a la célebre historia del anillo de Giges:

“(...) difficultoso es de creer lo que se dize del anillo de Giges, rey que fue de Lidia... El qual escriben que tenia tan propiedad, que, teniéndolo en el dedo, si escondía la piedra dél, rebolviéndola hazia la palma de la mano, se hazía invisible el Giges y él vía a todos; y, en

\footnotetext{
${ }^{34}$ Reprueba Ciruelo: “... algunos nigrománticos llaman al diablo haziendo vn cerco o circulo en tierra, con ciertas feñales. Otros en vna redoma llena de cierta agua. Otros en vn efpejo de alinde. Otros en piedras preciofas de anillos... y de otras infinitas maneras, por los quales invocado el diablo les aparece en muchas y diuerfas maneras..." (CIRUELO, 1628, 44).

${ }^{35}$ Aún tres décadas después de fallecer Mexía, el teólogo toledano Juan de Horosco y Covarrubias (1540-1610) en su Tratado de la verdadera y falsa prophecia , criticó el “....adiuinar por anillos encerrando en ellos quien respondiese.” (HOROSCO Y COVARRUBIAS, 1588, 97v.)

${ }^{36}$ Por caso, una representación cultural extendida era atribuir poderes mágicos a la palabra escrita. Era usual llevar -debajo de la ropa- "nóminas" (pedazos de papel o pergamino portando palabras especiales, nombres de santos, oraciones, etc.), con los que se creía poder evitar el mal de ojo, enfermedades, peligros de los viajes, etc. La venta de estos objetos materiales/culturalesespecíficos alcanzaba, en ocasiones, magnitud (cuando falleció el impresor Jacobo Cromberger en 1528, en su almacén en Sevilla se encontraron ocho mil pliegos impresos con nóminas mágicas y otras mil versiones de lujo coloreadas a mano (GRIFFIN, 2009, 313).

${ }^{37}$ TAUSIET, 2007, 49-57.

38 Citado en MONTER, 2002, 258. No entraremos en los relatos que, con variantes, desde tiempos grecoromanos y circulando entre judíos, cristianos y musulmanes, vincularon a Salomón con un anillo mágico. Ya Flavio Josefo había escrito sobre el judío Eleazar, quien, en tiempos de Vespasiano (69-79 d.C.), liberaba a los posesos de los daemones usando el "anillo de Salomón" (Antiquitates iudaicae, 8: 2).

${ }^{39}$ Abordamos este asunto en detalle, pues la construcción e invención discursiva de genealogías de autoridades versadas en saberes antiguos para legitimar apologéticamente prácticas y representaciones esotéricas específicas, fue señalada como ítem importante de estudios dentro de nuestro campo. Ver KILCHER, 2010, XIII.
} 
tornando a rebolver el anillo, veían todos a él (...) El auctor de esto fue el grande philósopho Platón, en el segundo de los libros de República (......"40

Platón (circa 427-347 a.C.) en la República (Lib. II, 359a-360d), había desplegado esa historia del anillo mágico de Giges que le otorgaba invisibilidad en la voz de Glaucón. ${ }^{41} \mathrm{Y}$ este topos de la invisibilidad circuló en la literatura posterior adoptando un sinfín de variantes, estando vigente incluso en épocas de nuestro astrólogo y mago natural. ${ }^{42}$

Mexía se apropia además de otro relato de los Antiguos -ahora sin dudar sobre la veracidad de la historia- para ejemplificar que, con estos anillos, se puede preservar la vida: "Y destos tales anillos fueron aquéllos siete escrive Philóstrato que Apolonio Tianeo tuvo, que el rey Yarcas de India le avía dado; con la virtud de los quales, poniéndose cada día uno dellos, conservó su juventud y mocedad (...)."43

Aquí refiere a Filóstrato de Atenas (170-245), quien en Vida de Apolonio (Lib. III), escribió que éste debatió sobre adivinación astrológica con Iarchas y que, en el transcurso de la disputa, aquél le regaló siete anillos (cada uno con el nombre de uno de los siete planetas) para que los usase un día de la semana según correspondiera astrológicamente y a fin de evitar su envejecimiento. ${ }^{44}$

Tras citar a Platón y Filóstrato, en tres párrafos específicos Mexía enumera una serie de autoridades y textos, sin profundizar en sus alusiones pero argumentando que "tractan en particular" el tema:

“(...) libros ay excelentes que dello tractan en particular: como es Aristóteles, en el que hizo De las piedras (aunque algunos dubdan ser suyo); y Alberto Magno, en el De las cosas minerales; Marbodeo, poeta, en el De las piedras preciosas; Serapión, en el De los simples, sant Ysidro, en el diez y seys de sus Etimologías; Bartolomé Anglico, De las propiedades de las cosas; y, sobre todos, Leonardo Camillo, en El espejo de las piedras, y Plinio, en diversas partes... y otros auctores, que dexo por no alargarme (...),"45 "Leonardo Camillo, en el libro a quien llama Espejo de piedras, lo escrive y enseña, y Cornelio Agripa, en el De Oculta filosophia, y Alberto Magno; y Tebit, grande philósopho, escrivió también esto (...)." ${ }^{, 46}$ "Verdad es que muchos anillos ponen algunos auctores, en que no tienen respecto al cielo (al menos, no lo escriven), sino solamente a la naturaleza de la piedra y a la imagen (como son

\footnotetext{
${ }^{40}$ MEXÍA, IV, 1, 315.

${ }^{41}$ Glaucón relataba que, tras sobrevivir a tormentas y terremotos que azotaban su territorio, un pastor encontró por accidente en el interior de un hoyo profundo -abierto por la fuerza de la naturaleza-, un cadáver que portaba un anillo de oro y, al apoderarse de él, descubrió que manipulándolo podía volverse ora invisible ora visible (por lo que, en complot con la reina, se acercó al rey, lo asesinó aprovechando ese poder y se quedó con su reino). El relato sobre el "Anillo de Giges" ha recibido enfoques y debates -que sería arduo citar aquí. En lo que concierne a nuestra temática, ver PHILIPPAKIS, 1997, 27-40; SHELL, 1989, 21-84.

${ }^{42}$ Un contemporáneo de Mexía, Ludovico Ariosto (1474-1533), en su poema Orlando Furioso (1506-1516), cuando escribió sobre las aventuras del paladín Orlando en pos de su amada Angélica -en un contexto de combates entre cristianos e infieles-, desarrolló cómo uno de los caballeros se infiltra entre los moros sin ser visto, precisamente, gracias a la invisibilidad que le otorga un anillo escondido en su boca (cap. VII, versos 3435). En cuanto a la cuestión mágica en Ariosto, Ver KISACKY, 2000; KISACKY, 1996, 253-273; CRAIG, 1988, 20-45.

${ }^{43}$ MEXÍA, IV, 2, 322.

${ }^{44}$ Remitimos a la traducción inglesa: The Life of Apollonius of Tyana, by Philostratus, de CONYBEARE, 1912, 322-323.

${ }^{45}$ MEXÍA, IV, 2, 319-320.

${ }^{46}$ Ibidem, 321-322.
} 
Rogiel, en el libro que llamó De las alas, y los que Leonardo Camillo refiere a Thetel y de Cael, y los del libro sin auctor, que, por darles auctoridad, intitulan De Salomón) (....."47

¿Cuáles son las referencias de estos autores y textos aludidos en la "Silva"?

Aristóteles y Plinio surgen en primer lugar entre las autoridades antiguas.

Mexía duda si el "De las piedras" había sido escrito por Aristóteles (384-322 a.C.). Es que, en la Edad Media circulaban cantidad de versiones de textos mágicos atribuidos al Filósofo. Y uno de ellos, el De lapidibus, que describía propiedades mágicas naturales de piedras y gemas, ya se mencionaba en versión árabe tan temprano como en el siglo IX. ${ }^{48}$

Por su parte, la alusión a "Plinio" es laxa. Mexía no identificó el título de su célebre texto, aunque precisó con acierto que escribió sobre este asunto "en diversas partes (...)". El conjunto de libros que componían la Naturalis historiae (circa 77 d.C.) de Gaius Plinius Secundus ${ }^{49}$, era célebre y circulaba desde tiempos medievales, adoptando diversas impresiones en la centuria previa a la "Silva". ${ }^{50}$ Específicamente en el libro XXXVII, el sabio romano había dedicado setenta y ocho capítulos a detallar propiedades mágicas de las piedras y, en el XXXVIII, había escrito sobre las virtudes de los anillos mágicos: entre sus ejemplos, destacó que, como los lagartos recuperaban la vista naturalmente tras ser cegados, para sanar ojos débiles o llorosos, debía ubicarse un lagarto ciego junto a un anillo de hierro (u oro) en el mismo recipiente (de forma que, cuando éste recuperase su vista, los anillos adquirirían igual poder y podían ser usados a tal fin). ${ }^{51}$

Habiéndose apropiado de aquél universo cultural pagano, Mexía recupera también un célebre erudito cristiano de los siglos VI-VII.

Refiriendo a las "diez y seis de sus Etimologías" está citando a las Etymologiarum libri $X X$ de Isidoro de Sevilla (560-636). Aquí Mexía es muy preciso en su referencia de autoridad, pues identifica el título del texto y particulariza además a cuál de todos los libros isidorianos remite. Y, efectivamente, en el libro XVI (en el capítulo 15), Isidoro describió creencias paganas que atribuían poderes mágicos a piedras y gemas, ${ }^{52}$ siendo una de sus fuentes la citada Naturalis historiae. ${ }^{53}$ Pero, esta apropiación que Mexía usa para legitimar prácticas y representaciones con anillos mágicos, encierra una táctica que oculta al lector de la "Silva" la posición isidoriana eminentemente hostil respecto de la magia: no sólo en el libro VIII (en el capítulo 9) Isidoro había atribuido la invención de la magia y su difusión a los "ángeles

\footnotetext{
${ }^{47}$ Ibidem, 323.

48 THORNDIKE, 1922, 243. Fue en realidad uno de los discípulos de Aristóteles, Teofrasto (circa 372-287), quien había escrito el De lapidibus, para referenciar a setenta clases de piedras diferentes y señalar virtudes mágicas de algunas de ellas (EICHHOLZ, 1965).

49 “PLINIO EL VIEJO", 23-79.

${ }^{50}$ Venecia, 1469, 1472, 1487, 1491 y 1499; Roma, 1473; Parma, 1481. Ver THORNDIKE, 1929, 53.

${ }^{51}$ Escribe Plinio el Viejo: “...alii terram substernunt lacertae viridi excaecatae et una in vitreo vase anulos includunt e ferro solido vel auro. cum recepisse visum lacertam apparuit per vitrum, emissa ea anulis contra lippitudinem utuntur, alii capitis cinere pro stibi ad scabritias. quidam viridem, collo longo, in sabulosis nascentem comburunt et incipientem epiphoram inungunt, item glaucomata." (extraído de JAN; MAYHOFF 1892-1909).

52 THORNDIKE, 1929, 627.

${ }^{53}$ DRAELANTS, 2019, 171
} 
malvados", ${ }^{54}$ exigiendo a los cristianos rechazar esas prácticas, ${ }^{55}$ sino que, bajo su dirección, el IV Concilio de Toledo (633) -en su canon XXIX- había prohibido a los clérigos contactar magos, augures, arúspices y sortílegos. ${ }^{56}$

Otro recurso de Mexía fue apropiarse de dos sabios de la tradición árabe.

Con "Tebit, grande philósopho", Mexía estaba, al mismo tiempo que mostrando su admiración, castellanizando el nombre del astrólogo sabeo Thabit ibn Kurrah ibn Marwan ibn Karaya ibn Ibrahim Thebit ibn Marines ibn Salamanos -Abu Al Hasan- Al Harrani. ${ }^{57} \mathrm{Su}$ manuscrito, centrado en los talismanes con imágenes astrológicas (que podían ser grabadas en cualquier gema pues su eficacia suponía conocer y respetar configuraciones celestes propicias), circuló en dos versiones traducidas al latín con el título de De ymaginibus. ${ }^{58}$ Dado que ambas traducciones diferían entre sí (en una el énfasis de la práctica astral estaba puesto en el creador del talismán que hacía descender las virtudes celestes más que en las prácticas dirigidas a espíritus planetarios; en la otra existían rezos a espíritus), ${ }^{59}$ por lo escueto de la mención no podemos establecer a cuál de las dos alude en la "Silva".

Cuando Mexía escribe "Serapión, en el De los simples", está refiriendo a Ibn Sarabi (conocido como Serapión el Joven), quien pudo haber vivido en el siglo XII y del que poco se sabe excepto que escribió De Simplicibus Medicamentis para recopilar medicinas griegas y árabes. Este manuscrito medieval fue traducido en 1288 del árabe al hebreo y de ahí al latín (respectivamente, por Abraham el judío y Simón de Génova -médico del Papa Nicolás IV). ${ }^{60}$ Inclusive, para los años en que vivió Méxia, existía una versión impresa: el Liber Serapionis Aggregatus in Medicinis Simplicibus (Milán, 1473). ${ }^{61}$

Ahora, además de esos eruditos que remiten a los Antiguos y al universo cultural árabe (sabeo o islamizado), Mexía añade tres cristianos: "Marbodeo", "Alberto Magno" y "Bartolomé Anglico".

En el primer caso, refiriere al obispo de Rennes, Marbodius o Marbod (?-1123), quien, en su De lapidum naturis recordó el poder mágico natural de sesenta piedras y, citando el libro antes mencionado De lapidibus atribuido a Aristóteles, precisó que, si son ubicadas en

\footnotetext{
${ }^{54}$ Escribe Isidoro en Etymologiae, VIII, 9, 3: "Itaque haec vanitas magicarum artium ex traditione angelorum malorum in toto terrarum orbe plurimis saeculis valuit" (extraído de PRIETO, 2005, cita 110)

${ }^{55}$ Etymologiae, VIII, 9, 31 "In quibus omnibus ars daemonum est ex quadam pestifera societate hominum et angelorummalorum exorta. Unde cuncta vitanda sunt a Christiano, et omni penitus execratione repudianda atque damnanda" (extraído de PRIETO, 2005, cita 113).

${ }^{56}$ Establece el Concilio: "Si episcopus quis, aut presbyter, sive diaconus, vel quilibet ex ordine clericorum, magos, aut aruspices, aut ariolos, aut certe augures, vel sortilegos, vel eos qui profitentur artem aliquam, aut aliquos eorum similia exercentes, consulere fuerit deprehensus, ab honore dignitatis suae depositus monasterii curam excipiat, ibique perpetua poenitentia deditus scelus admissum sacrilegii luat." (extraído de VIVES, 1963, 203)

${ }^{57}$ Thabit nació en Harrán en 836 y en Bagdad se dedicó a la astrología y la traducción de textos griegos al árabe y al siríaco hasta su muerte ocurrida circa 901.

${ }^{58}$ Fue traducido primero del árabe al latín en forma independiente por Johannes Hispalensis (primera mitad del siglo XI) y por Adelardus Bathensis (circa 1080-1150) y, luego impreso como De tribus imaginibus magicis (Frankfurt, 1559). Ver PINGREE, 1987, 74-75; CARMODY, 1960, 180 y ss; THORNDIKE, 1929, 661-666. ${ }^{59}$ FORSHAW, 2015, 40.

${ }^{60}$ LECLERC, 1876, 155

${ }^{61}$ Tras fallecer Mexía en 1551, se imprimirá en Venecia el Serapion de Simplic. Medicam. Historia Libri VII (1552). Ver The Penny Cyclopadia of the Society for the Diffusion of Useful Knowledge, Londres, 1833-1843, 260; THORNDIKE, 1929, 611, cita 1.
} 
el cuello o en un dedo, servían para contrarrestar la epilepsia. ${ }^{62} \mathrm{Si}$ la editio princeps del De lapidum naturis circulaba en tiempos de Mexía -fue publicada en 1511;63 una traducción castellana (adaptada de la versión original, con notables semejanzas pero no igual) ya existía desde el siglo XV. ${ }^{64}$ Por ende, la identificación del texto de Marbod por su título "De las piedras preciosas" en la "Silva", puede haber sido una castellanización de la versión latina o una alusión directa a esta traducción castellana.

En el segundo, al escribir “Alberto Magno, en el De las cosas minerales”, Mexía apunta al Liber de mineralibus et lapidibus, del que existen versiones disímiles con títulos diferentes ${ }^{65}$ pero que fue escrito circa 1250 por quien llegará a ser obispo de Ratisbona, el dominico Albertus Teutonicus o Albertus Magnus (1200?-1280). ${ }^{66}$ En su texto, Alberto Magno había descrito la confección de talismanes, subrayando la necesidad de observar la impresión de la figura en función de la configuración de los cielos propicia, a fin de que los poderes celestes fluyan hacia el objeto y, al combinarse entre sí, efectúen maravillas. ${ }^{67}$ Es que, como bien fue señalado, el dominico distinguía las acciones de la naturaleza de las del arte humano: aunque ciertos objetos estaban dotados naturalmente de propiedades ocultas, si al desplegar su propio arte el hombre observaba con precisión el momento astrológico favorable también proveía poderes celestes al objeto, pues insertaba intencionalmente su acción mediadora en el curso natural de las cosas. ${ }^{68}$

En la tercer referencia, "Bartolomé Anglico, De las propiedades de las cosas”, Mexía alude al franciscano inglés Bartholomeus Anglicus (circa 1203-1272), del que poco se sabe excepto que, en 1231, se trasladó a la ciudad de Magdeburgo ${ }^{69}$ donde escribió su De proprietatibus rerum ${ }^{70}$ (entre 1240 y 1259). ${ }^{71}$ Concretamente en el libro XVI ("De lapidibus et metallis") Bartolomé Anglico describió propiedades mágicas de ciertas gemas. ${ }^{72}$ Este texto obtuvo varias traducciones (italiano, 1309; francés, 1372; provenzal, 1391; inglés, 1398; neerlandés, 1485) y, cuando Mexía escribe su "Silva" en 1540, ya existía inclusive una traducción castellana: en 1494 apareció la de Vicente de Burgos (que la efectuó a partir de la traducción francesa de 1372 pero cotejando con el manuscrito latino original), ${ }^{73}$ la cual fue, a su vez, reimpresa en 1529 por Gaspar de Ávila en Toledo. ${ }^{74}$

\footnotetext{
${ }^{62}$ Escribe Marbod: "Aristoteles in libro de Lapidibus ait: "Smaragdus suspensus in collo vel portatus in digito defendit a casu epilepsiae suspecto." (citado en KLEIN-FRANKE, 1970, 139).

${ }^{63}$ FREUDENTHAL, \& MANDOSIO, 2014, 20.

${ }^{64}$ NUNEMAKER, 1938, 62-67.

65 THORNDIKE, 1929, 524, cita 3.

${ }^{66}$ COLLINS, 2010, 15.

${ }^{67}$ Escribe Alberto Magno: "Ex his autem de necessitate concluditur, quod si observare ad coelestem figuram imprimatur figura in materia per naturam vel artem, quod coelestis figurae aliqua vis influitur operi naturae vel artis... Hac ergo industria considerata primi praeceptores et professores physici gemmas et imagines metallicas ad imagines astrorum observatis temporibus quando vis coelestis fortissima ad imaginem eamdem esse probatur, ut puta coelestibus multis virtutibus admixta, sculpi praecipiebant, et mira per tales imagines operabantur" (extraído de BORGNET, 1890-1895, V, 51-52) -existe traducción al inglés (WYCKOFF, 1967).

${ }^{68}$ WEILL-PAROT, 2010, 215-218.

${ }^{69}$ BEONIO, \& FUMAGALLI, 1981, 9-10 y 44.

${ }^{70}$ Dictionary of national biography: from the earlies times to 1900, 1885-1901, 409-411.

${ }^{71}$ JOURDAIN, 1843, 33 y 358-360.

72 THORNDIKE, 1929, 436-437.

${ }^{73}$ SANCHEZ GONZALEZ DE HERRERO, 2008, 349-366; STEELE, 1893, 1.

${ }^{74}$ Ver Liber de proprietatibus rerum en romance : hystoria natural do se trata las p[ro]piedades d'todas las cosas ... / trasladado de latin en romance por fray Vicente de Burgos ... Toledo: en casa de Gaspar de Auila: a costa y espensas del noble ... Ioan Thomas Fabrio, 1529.
} 
Por último, Mexía citó los textos de dos contemporáneos: "Leonardo Camillo, en el libro a quien llama Espejo de piedras (...) y Cornelio Agripa, en el De Oculta filosophia (...)."

El célebre Heinrich Cornelius Agrippa von Nettesheim (1486-1535), en el capítulo XLVII "De annulis, eorum compositionibus" del libro I de su De occulta philosophia libri tres (escrito en 1510, publicado en 1533 y con múltiples reediciones posteriores), describió ciertos anillos que contrarrestaban enfermedades, venenos, enemigos y demonios y relató la manera de confeccionarlos acorde a configuraciones astrológicas propicias. Remitió para ello a las historias de los anillos mágicos de Iarchas (según Filóstrato), Moisés y Salomón (según Flavio Josefo) y Gilges (según Platón). Como vimos, dos de esas tres historias fueron citadas también por Mexía.

Camilo Leonardi (¿-1532?), escribió su Speculum lapidum clarissimi artium et medicine doctoris Camilli Leonardi Pisaurensis (Venecia, 1502). ${ }^{75}$ Este texto adquirió una posición central en el despliegue argumental de autoridades de Mexía -manifiesto al escribir en los apartados que venimos analizando, que Leonardi estaba por "sobre todos". Es que en el Speculum desfilaban más de dos centenares de gemas caracterizadas por sus respectivas virtudes mágicas y casi trescientas imágenes que podían ser grabadas en cada una. ${ }^{76}$ Para ello, Leonardi citó a la Naturalis Historiae de Plinio, las Etymologiae de Isidoro de Sevilla y el De Lapidibus de Marbod $;{ }^{77}$ pero también a Aristóteles, Alberto Magno y Serapión: ${ }^{78}$ son las mismas seis referencias que ya observamos en la "Silva".

Ahora, basado en Leonardi, Mexía refiere asimismo lo que interpreta son otros dos textos vinculados al tema de los anillos mágicos y astrológicos, cuando escribe "...y los que Leonardo Camillo refiere a Thetel y de Cael".

Los nombres "Thetel" y "Cael" remiten a un problema histórico. Fue mencionado que el lapidario astrológico De sigillis in lapidibus sculptis, escrito por el judío "Zael" (conocido como Thetel), es la referencia de Leonardi, ${ }^{79}$ quien se habría apoyado en la traducción germana de $1350 .{ }^{80}$ Empero, también fue resaltado la existencia de un complejo de manuscritos similares circulando en la Edad Media con varios títulos (Liber sigillorum; Liber de sculpturis lapidum; etc.) que fueron traducidos a varias lenguas, atribuyéndose su escritura a diversas épocas ${ }^{81}$ y con autores entre los que destaca uno reiterado con ligeras variantes: "Techel", "Theel", "Tetel", "Thetel", "Thechel", "Techef", "Tochel", "Cehel”, "Cheel", "Cethes", "Cethel", "Chael", "Detel", "Ethel", "Rechel", "Ghehel", "Asechel". 82 Mexía entonces estaría haciendo referencia indirecta a este lapidario del que aún quedan dudas sobre su datación y autor.

Párrafo aparte merece la laxa expresión de Mexía “...los del libro sin auctor, que, por darles auctoridad, intitulan De Salomón", pues eran gran cantidad los textos de magia "sin auctor" que eran atribuidos a Salomón y que circulaban desde el siglo XII. ${ }^{83}$ Quizás el más

\footnotetext{
${ }^{75}$ El texto fue impreso nuevamente en 1516 y 1533. Ver LECOUTEUX \& MONFORT, 2002, 23.

${ }^{76}$ LEOPARDI, 2016, 102 y 110

${ }^{77}$ LEOPARDI, 2016, 104-105

${ }^{78}$ LECOUTEUX \&, MONFORT, 2002, 24.

${ }^{79}$ DRAELANTS, 2019, 171

${ }^{80}$ LECOUTEUX \& MONFORT, 2002, 237 y ss.

${ }^{81}$ MESLER, 2014, 75-143

${ }^{82}$ MESLER, 2014, 90

${ }^{83}$ Ver PINGREE, 1994, 39-56; VERONESE, 2019, 187-200.
} 
célebre fue la Clavícula Salomonis: en tiempos de Mexía la ortodoxia lo prohibía y, si era descubierto, podía ser confiscado (como aconteció en Gran Canaria en 1527). ${ }^{84}$

Por último, mención especial merece la expresión "Rogiel". Castro especuló que Mexía quizás estuviese refiriendo a "Alí ben Ragel". ${ }^{85}$ Se trataría así de una alusión al astrólogo magrebí Abu Ali ibn ar-Rigal -o Abu-Hassan 'Ali ibn Abi-Rigal- (circa 965-1037), conocido entre los cristianos como Abenragel y autor del Kitāb al-bāri' fi akhām an-nujūm. Ese texto, traducido al castellano con el título Libro conplido en los iudizios de las estrellas en $1254,{ }^{86}$ fue "posiblemente el manual astrológico más utilizado" en la península hasta el siglo XV ${ }^{87}$ y tuvo tanta circulación que, incluso, el rey de Aragón Pedro el Ceremonioso (1319-1387) tenía un ejemplar en su biblioteca. ${ }^{88}$

Sin embargo, Mexía precisa en su "Silva" un nombre y un título de libro: "Rogiel, en el libro que llamó De las alas". Por ende, quizás podamos plantear que estaría tomando la referencia del mencionado Speculum Lapidum donde, en el Libro III (capítulo XIV, "De imaginibus magicis (...) quae a Ragiel positae sunt”), Leonardi había exaltado a un tal "Ragiel" identificando aquél texto titulado "libro alarum". ${ }^{99}$ De ser correcta esta hipótesis contraria a la de Américo Castro-, la mención sobre "el libro que llamó De las alas" podría estar vinculada entonces quizás al Liber Razielis -es decir, sería una referencia de Mexía a la magia astral judía medieval. Es que no sólo este texto estaba disponible en la península ibérica tres siglos antes de la escritura de la "Silva" -fue compilado circa 1259 merced a las traducciones de manuscritos hebreos efectuadas (quizás por Juan d'Aspa) en épocas del mencionado rey Alfonso $\mathrm{X}^{90}$ (a los que se añadieron escritos procedentes de tradiciones greco-helénicas) $;{ }^{91}$ sino que, en un ejemplar latino conservado del siglo $\mathrm{XV}$, se observó que lo integraban varios libros ${ }^{92}$ y que, en el segundo de ellos, se describían específicamente las virtudes de ciertas gemas esculpidas con imágenes. ${ }^{93}$

Mexía estaría así citando como fuente de autoridad un texto que hacía al menos dos siglos que la ortodoxia relacionaba con la nigromancia demoníaca y la idolatría. Ya en un proceso inquisitorial desarrollado en Barcelona entre 1356 y 1360, el nombrado Eymeric quemó un ejemplar del Liber Razielis alegando su relación con la invocación demoníaca. ${ }^{94}$

\footnotetext{
${ }^{84}$ DAVIES, 2009, 55.

${ }^{85}$ Castro argumentó que Mexía ya lo habría mencionado antes en la "Silva" (I, 36, 483), al escribir "Alí ben Ragel en el libro Judiciario...”. Ver CASTRO, 1989, 323, nota 25.

${ }^{86}$ El traductor fue el erudito judío Yehuda ben Moshe ha-Kohen en tiempos de Alfonso X (1221-1284). Ver DE VICENTE GARCIA, 2002, 129-130.

${ }^{87}$ SAMSO, 1983, 25

${ }^{88}$ GARCIA AVILES, 1999, 100

89 “...maxime ille summus Ragiel in libro alarum”. (LEONARDI, 1717, 156)

${ }^{90}$ GARCIA AVILES, 1997, 29, cita.33.

${ }^{91}$ GIRALT, 2014, 229.

${ }^{92}$ Libro de la clave (fols. 13r ss.) 2) Libro del ala (fols. 21r ss.) 3) Libro de los sahumerios (fols. 37 ss.) 4) Libro de los tiempos (fols. 64 ss.) 5) Libro de la purificación del cuerpo (fols. 87 ss.) 6) Libro de los cielos (fols. 96 ss.) 7) Libro de las imágenes (fols. 139v-202v). En la introducción son identificados en latín de la siguiente forma: "Iste primus liber dicitur Clavis. Secundus dicitur Ala. Tertius dicitur Thymiama. Quartus dicitur Liber temporum. Et quintus dicitur Liber mundicie et abstinentie. Sextus dicitur Liber Samaym, quod vult dicere liber celorum. Septimus dicitur Liber magice, quia locitur de virtutibus ymaginum", Ver GARCIA AVILES, 1997, 27, cita. 26.

${ }^{93}$ GARCIA AVILES, 1997, 32.

94 "Frater Nicolaus Eymerici inquisitor et Arnaldus de Buschetis condemnarunt publice Barchinone et comburi fecerunt quendam magnum et grossum librum daemonum invocationum in septem partes distinctum qui
} 
Y un siglo más tarde, el obispo de Cuenca, inquisidor y confesor del Rey Juan II de Castilla (1405-1454), Fray Lope de Barrientos (1382-1469), en su Tractado de las espeçias de adivinanças (circa 1450) escribió hostilmente contra el Liber Raziel, alegando que carecía de fundamento y que contenía sacrilegios reprobados por la "Sacra Escriptura". ${ }^{95}$

\section{Conclusiones}

Pedro Mexía, en tanto astrólogo y mago natural -y, por ende, representante del esoterismo español de la primera mitad de siglo XVI-, en su "Silva de varia lección" (1540) mencionó prácticas y representaciones con anillos mágico-astrológicos compatibles con las vigentes dentro y fuera de la península ibérica (citados, entre otros, por Torrella y Ficino). Esos objetos materiales y culturales podían tener "virtud y fuerça" si eran confeccionados con imágenes concordantes con configuraciones astrológicas propicias o si portaban piedras y gemas específicas. En la voz de Mexía, estos anillos adquirían un sentido positivo, pues permitían la protección contra daños hechiceriles y demoníacos, curar dolencias del cuerpo y emociones, prevenir contra impulsos sexuales instintivos, facilitar el dormir, el descanso y el sueño, identificar la virginidad en una mujer y proteger contra tempestades.

Ahora, en el marco cultural en el que se escribe la "Silva", una tradición discursiva hostil construida durante siglos por la ortodoxia cristiana impugnaba esas mismas prácticas y representaciones con anillos (relacionándolos con la superstición pagana primero y, desde el siglo XI y hasta los tiempos en que vivió Mexía, con un llamado al diablo, un vínculo a demonios, el dominio de espíritus o un pacto con el demonio). Los discursos de autoridad hostiles de Agustín de Hipona, Tomás de Aquino, Juan XXII, Nicolás Eymeric, Alonso Manrique de Lara y Solís y Pedro Ciruelo respecto de estos objetos, se tradujeron en prácticas políticas represivas concretas: en la península ibérica, prohibiciones -e incluso la quema- de libros que los mencionasen y persecuciones contra quienes usasen estos anillos.

Frente a este cuadro, al desarrollar el tópico del uso de anillos mágico-astrológicos, nuestro mago y astrólogo no confrontó en su "Silva" con aquellas voces ortodoxas, pero desarrolló un recurso argumental determinado: se apropió de los textos de los Antiguos, de eruditos medievales y de dos contemporáneos (Platón, Filóstrato, Plinio, Isidoro, Tebit, Serapión, Marbod, Alberto Magno, Bartolomé Anglico, Leonardi, Agrippa) así como de lapidarios (atribuidos a Aristóteles, Salomón, Thetél) y de -quizás- el Liber Razielis y los integró en una unidad de sentido particular. Su operación radicó en crear una compleja red de autoridades procedentes de diversas tradiciones culturales (greco-romanas, judías, árabes -sabeas o islamizadas- y cristianas), con la que intentó apologéticamente legitimar estas prácticas y representaciones específicas.

Así, las prácticas y representaciones relacionadas con el uso de anillos mágicos y astrológicos carecían, en la España de Carlos V, de sentido unívoco. Su significado era uno de los terrenos de disputa política dentro del campo cultural de la época; un sitio particular

intitulatur Liber Salomonis, in quo erant scripta sacrificia, oraciones, oblationes et nefaria quamplurima fieri daemonibus consultata." (extraído de EIMERIC., 1578, 226).

${ }^{95}$ Escribe Lope de Barrientos: "De lo qual resulta que esta arte mágica e aqueste libro Raziel susodicho non tiene fundamento ni eficaçia alguna pues por ella non pueden los angeles ser constrenidos a venir cuando fueren llamados nin pueden reuelar las cosas aduenideras... E puesto que en dicho libro Raziel se contienen muchas oraciones devotas pero estan mescladas con otras muchas cosas sacrílegas e reprouadas en la Sacra Escriptura. Este libro es mas multiplicado en las partes de España que en las otras partes del mundo... " (extraído de ÁLVAREZ LÓPEZ, 2000, 117). 
en el mapa general de la lucha constante en torno a lo que era posible pensar, hacer y decir respecto de la magia natural y la magia astral.

\section{REFERENCIAS BIBLIOGRÁFICAS}

Fuentes primarias

AGUSTÍN DE HIPONA, De doctrina christiana (ed. Bilingüe Obras de San Agustín, Madrid, Biblioteca de Autores Cristianos, 1965).

Albertus Magnus Book of Minerals (ed. D. Wyckoff, Oxford, Clarendon Press,1967).

De mineralibus D. Alberti Magni, Ratisbonensis Episcopi, Ordinis Praedicatorum, opera omnia (ed. A. Borgnet, Paris, apud Ludovicum Vives̀, 1890- 1895).

FRANCISCO PEÑA, Nicolás Eimeric. El Manual de los Inquisidores, Barcelona,Muchnik. 1983.

HEINRICH CORNELIUS AGRIPPA, De occulta philosophia libri tres (1510), Lugduni, apud Godefridum \& Marcellum Beringos fratres, 1550.

JOHANNES ESCHUID, Summa astrologie iudicialis, Venetiis, Francisci Bolani, 1489.

JUAN DE HOROSCO Y COVARRUBIAS, Tratado de la verdadera y falsa prophecia,Segovia, Juan de la Cuesta, 1588.

MARSILIO FICINO, De Vita Coelitus Comparanda, 1489 (ed. bilingüe latín-inglés de C. Kaske y J. Clark, Arizona, The Renaissance Society of America, 1998)

NICOLAU EIMERIC, Directorium inquisitorum, Roma, In Aedibvs Pop Rom, 1578.

Les pierres talismaniques. Speculum Lapidum Livre III. Camillo Leonardi (ed.Claude Lecouteux \& Anne Monfort, texte, traduction, commentaire et annotations. Paris, Presses de 1'Université de Paris-Sorbonne, 2002).

LOPE DE BARRIENTOS, Tractado de la adivinança (ed. F. Álvarez López, Arte mágica y hechicería medieval. Tres tratados de magia en la corte de JuanII, Valladolid, Diputación de Valladolid, 2000).

PEDRO MEXÍA, Silva de Varia Lección (ed. Américo Castro, Madrid, Cátedra, 1989). Diálogos o Coloquios (ed. Antonio Castro Díaz, Madrid, Cátedra, 2004).

PEDRO COMESTOR, "Historia Scholástica” (ed. Migne, J. P., Patrología latina,Paris, 1855).

PEDRO CIRUELO, Reprobación de las supersticiones y hechizerías (1538), Barcelona, 1628.

The Life of Apollonius of Tyana, by Philostratus (trad. F.C. Conybeare, LCL.,1912).

Speculum lapidum clarissimi artium et medicine doctoris Camilli Leonardi Pisaurensis (1502; ed. Hamburgo, 1717).

Plinii Secundi Naturalis Historiae Libri XXXVII (ed. L. Jan; C. Mayhoff, 6 vols. Editio stereotypa editionis prioris 1892-1909, Stuttgart-Leipzig, Teubner).

Theophrastus, De Lapidibus (ed. D. E. Eichholz, Oxford, Oxford University Press, 1965). 


\section{Bibliografía}

BAILEY, Michael, "From Sorcery to Witchcraft: clerical conceptions of Magicin the Later Middle Ages", Speculum, 76, 4, 2001, 960-990.

, Magic and Superstition in Europe. A concise history from Antiquity to the Present, USA, Rowman \& Littlefield Pub. Inc., 2007.

BEONIO, Maria; FUMAGALLI, Brocchieri, Le enciclopedie dell'occidente medievale, Turín, Loescher, 1981.

BOUREAU, Alain, Satan the Heretic The Birth of Demonology in the MedievalWest (2006), Chicago, University of Chicago Press, 2014.

BUBELLO, Juan, "El aporte de la historiografía francesa actual en torno al centenario debate sobre el concepto de Magia", en González, María Luz, Problemas de Historia Moderna. Cuestiones historiográficas, tendenciasen la investigación, Mar del Plata, UNMdP, 2005, 73-104.

"Esoterismo y política de Felipe II en la España del Siglo de Oro.Reinterpretando al círculo esotérico filipino en El Escorial: Juan de Herrera, Giovanni Vicenzo Forte, Diego de Santiago, Richard Stanihurst", Veredas da História, III, 2, 2010. Url acceso: https://docplayer.es/ 7324893-V-e-r-e-d-a-s-d-a-h-i-s-t-o-r-i-a.html

, "Notas sobre las relaciones entre absolutismo católico, polémicas antimágicas y esoterismo en la España del XVI: el caso de Felipe II y Juan de Herrera", en González, María Luz, (comp.), Temas y perspectivas de Historia Moderna, Mar del Plata, UNMdP, 2011, 231241.

"Magia y polémicas antimágicas en la España bajo medieval. Enrique de Villena, su Tratado de fascinación o de aojamiento y los límites de la ortodoxia cristiana", Revista Prohistoria, 17, 2012, 1-24.

,"El 'Arte Separatoria' (1598) de Diego de Santiago. Un alquimista en la corte de Felipe II", en González, María Luz (comp.), HistoriaModerna: tendencias y proyecciones, Mar del Plata, UNMdP, 2013, 169-179.

"Sacando a luz lo oculto en la naturaleza': astrología y alquimiade Diego de Santiago en la corte de Felipe II", en González, María Luz (ed.) Historia Moderna. Procesos y representaciones, Mar del Plata, UNMdP, 2014, 189-197.

,"Arte separatoria e hijos del arte en las prácticas y representaciones de Diego de Santiago (Sevilla, 1598) y el lugar de España en elEsoterismo Occidental”, Anales de Historia Antigua, Medieval y Moderna, 49, 2015, 79-103.

"Apologética de la alquimia en la corte de Felipe II. Richard Stanihurst y su `El Toque de Alquimia`(1593)", Magallánica, 2, 4, 2016, 95-117.

"Esoterismo y religión en la España del Siglo XVI. Stanihurst,de Santiago y la defensa de la alquimia", Reflexão, 42, 2, 2017, 199-211.

"Cultura y política en la España temprano-moderna: la defensa de la alquimia por Richard Stanihurst y Diego de Santiago en la corte deFelipe II", en AAVV. Estudios en Historia Moderna desde una visión Atlántica, La Plata, UNLP, 2017b, 551-581.

"Some remarks on the study of the Cultural History of WesternEsotericism in Latin America", Rehmlac, 12, 1, 2020, 219-240.

"Magia natural y astrología merced al uso de anillos. Apropiación de los Antiguos, esoterismo y ortodoxia cristiana. Pedro Mexía y su Silvade varia lección (1540)”, en González, 
María Luz (ed.), Historia Moderna. Nuevos enfoques, nuevas perspectivas, Mar del Plata, UNMdP, 2019, 311-319.

BURUCÚA, José E., Corderos y elefantes: la sacralidad y la risa en la modernidad clásica. Siglos XV-XVIII, Buenos Aires-Madrid, Miño y Dávila, 2001.

CAMPAGNE, Fabián, Homo catholicus, homo superstitiosus. El discurso antisupersticioso en la España de los siglos XV a XVIII, Madrid-Buenos Aires, Miño y Dávila, 2002.

CARMODY, Francis J., The astronomical works of Thabit Ibn Qurra, Berkeley, University of California Press, 1960.

CASTRO, Américo, Pedro Mexía, Silva de Varia Lección, Madrid, Cátedra, 1989(Introducción).

CHARTIER, Roger, El mundo como representación, Barcelona, Gedisa, 1992.

CLOUSTON, W. A., "On the Magical Elements in Chaucer's Squire's Tale" en John Lane's Continuation of Chaucer's Squire's Tale (ed. from the original Ms. Version of 1616), F. J. Furnivall, Chaucer Society, 2nd. Series —23and 26-, London, 1888-1890.

COLLINS, David, "Albertus, Magnus or Magus? Magic, Natural Philosophy, and Religious Reform in the Late Middle Ages", Renaissance Quarterly, 63, 1, 2010, 1-44.

_- "Scholasticism and high medieval opposition to magic", en Page, Sophie; Rider, Catherine (eds.), The Routledge History of Medieval Magic, London, Routledge, 2019, 461475.

COPENHAVER, Brian, "Scholastic Philosophy and Renaissance Magic in the DeVita of Marsilio Ficino", Renaissance Quarterly, 37, 4, 1984, 523-554.

"Renaissance Magic and Neoplatonic Philosophy: `Ennead`4.3-5 in Ficino`s `De Vita Coelitus Comparanda"”, en Garfagnini, Gian (a cura di), Marsilio Ficino e il retorno di Platone., Firenze, Leo S. OlschkiEd., 1986, 351-369.

CRAIG, Cynthia, "Enchantment and Disenchantment: A Study of Magic in theOrlando Furisoso and the Gerusalemme Liberata", Comitatus: A Journalof Medieval and Renaissance Studies, 19, 1, 1988, 20-45.

DAVIES, Owen, Grimoires. A History of Magic Books, Oxford-New York, Oxford University Press, 2009.

DE MARTINO, Ernesto, Magia y civilización, Buenos Aires, El Ateneo, 1965.

DE VICENTE GARCÍA, Luis, "La importancia del Libro Conplido en los Iudiziosde las Estrellas en la Astrología medieval", Revista de Literatura Medieval, 14, 2, 2002, 117-134.

Dictionary of national biography: from the earlies times to 1900, London, Oxford University Press, Vol. 21, 1885-1901, 409-411.

DRAELANTS, Isabelle, "The notion of properties. Tensions between Scientia and Ars in medieval natural philosophy and magic", en Page, Sophie; Rider, Catherine (eds.), The Routledge History of Medieval Magic, London, 2019, 169-186.

FAIVRE, Antoine, L'ésoterisme, Paris, PUF, 1992.

Access to Western Esotericism, New York, SUNY. Press, 1994.

FLINT, Valerie, "The Demonization of Magic and Sorcery in Late Antiquity: Christian Redefinitions of Pagan Religions," en Ankarloo, Bengt; Stuart,Clark (eds.), Witchcraft and Magic in Europe: Ancient Greece and Rome,Philadelphia, University of Pennsylvania Press, 1999, 277-348. 
FORSHAW, Peter, "The Occult Middle Ages", en Partridge, Christopher (ed.), The Occult World, London-New York, Routledge, 2015, 34-48.

"From Occult Ekphrasis to Magical Art Transforming Text intoTalismanic Image in the Scriptorium of Alfonso X", en Kiyanrad, Sarah,et. al., (eds.), Bild und Schrift auf 'magischen' Artefakten, Berlin, De Gruyer, 2018, 15-48.

FREUDENTHAL, Gad; MANDOSIO, Jean-Marc, "Old French into Hebrew inTwelfth-Century Tsarfat: Medieval Hebrew Versions of Marbode's Lapidary”, Aleph, 14, 1, 2014, 11-187.

GARCÍA AVILÉS, Alejandro, "Alfonso X y el Liber Razielis: imágenes de la magia astral judía en el scriptorium alfonsî”, Bulletin of Hispanic Studies,74, 1987, 21-39.

, "Alfonso X y la tradición de la magia astral" en Montoya Martínez, Jesús; Domínguez Rodríguez, A. (coords), El Scriptorium alfonsí:de los Libros de Astrología a las 'Cantigas de Santa Maríá, Madrid, Ed.Complutense, 1999, 83-104.

GIRALT, Sebastiá, "Magic in Occitan and Latin in Ms. Vaticano, BAV, Barb., lat. 3589", Revue d' Histoire des Textes, IX, 2014, 221-273.

GRIFFIN, Clive, Oficiales de imprenta, herejía e Inquisición en la España del siglo XVI, Madrid, Ollero y Ramos eds., 2009.

HANEGRAAFF, Wouter, et. al., Dictionary of Gnosis and Western Esotericism,

Leiden-Boston, Brill, 2005.

HILL, Derek, Inquisition in the Fourteenth Century: The Manuals of BernardGui and Nicholas Eymerich, United Kingdom, York Medieval Press, 2019.

JOURDAIN, Amable, Recherches sur les anciennes traductions latines d'Aristotle, Paris, Joubert ed., 1843.

KIECKHEFER, Richard, Magic in the Middle Ages (1989), Cambridge, Cambridge University Press, 2014, $2^{\text {nd. edition. }}$

KILCHER, Andreas, "Introduction. Constructing Tradition in Western Esotericism", en Kilcher, Andreas (ed.), Constructing Tradition Means and Myths of Transmission in Western Esotericism, Leiden-Boston, Brill, 2010, IX-XV.

KISACKY, Julia, "Magic and Enchanted armaments: moral considerations in Boiardo and Ariosto", Forum Italicum: A Journal of Italian Studies, 30,2, 1996, 253-273.

, Magie in Boiardo and Ariosto, New York, Peter Lang Pub., 2000.

KLEIN-FRANKE, Felix, "The knowledge of Aristotle's Lapidary during the latin middle ages", Ambix, XVII, 3, 1970, 137-142.

MONTER, William, Frontiers of Heresy. The Spanish Inquisition from the Basque Lands to Sicily, (1990), Cambridge, Cambridge UniversityPress, 2002.

MENDOZA, José, "Breve introducción a las nociones de ciencia y arte de la magia en Tomás de Aquino. De la beatitud personal al retorcimiento espiritual", Thémata. Revista de Filosofía, 54, 2016, 149-174.

MESLER, Katelyn, "The Medieval Lapidary of Techel/Azareus on engraved stones and its Jewish appropriations", Aleph, 14, 2, 2014, 75-143.

NunEmaKeR, J., "A Comparison of the Lapidary of Marbode with a Spanish Fifteenth-Century Adaptation", Speculum, 13, 1, 1938, 62-67.

LECLERC, Lucien, Histoire de la Medicine Arabe, París, Ernst Leroux Ed., 1876. 
LEOPARDI, Liliana, "Erotic Magic: rings, engraved precious gems and masculine anxiety", en Moulton, Ian F. (ed.), Eroticism in the Middle Ages andthe Renaissance: Magic, Marriage, and Midwifery, Turnhout, Brepols, 2016, 99-130.

LIONARONS, Joyce, "Magic, Machines, and Deception: Technology in the "Canterbury Tales", The Chaucer Review, 27, 4, 1993, 377-386.

PAVIA, M., Drama of the Siglo de Oro: a study of magic, witchcraft and otheroccult beliefs, New York, Hispanic Institute, 1959.

PETERS, Edward, The magician, the witch and the law (1978), Philadelphia, University of Pennsylvania Press, 1992.

PHILIPPAKIS, K., "No Evil: The Story of Gyges in Herodotus and Plato", en Rubin, L. G. (ed.). Justice v. Law in Greek Political Thought, Oxford, Rowman \& Littlefield Publishers, INC. Lanham, 1997, 27-40.

PINGREE, David, "The Diffusion of Arabic Magical Texts in Western Europe"en Scarcia-Amoretti, B. (ed.), La diffusione delle scienze islamiche nel medio evo europeo, (Convegno Internazionale promosso dall'AccademiaNazionale dei Lincei e dal Dipart.di Studi Orientali, 1984), Roma, Accademia Nazionale dei Lincei, 1987, 57-103.

"Learned Magic in the Time of Frederick II", Micrologus, 2, 1994, 39-56.

PRIETO, Pablo, "Isidoro de Sevilla frente a los límites del conocimiento: etimología, astrología, magia”, Temas Medievales, 13, 1, 2005, 125-156.

SAMSÓ, Julio, “Introducción”, en Tratado de Astrología atribuido a Enrique de Villena (ed. Pedro M. Cátedra), Barcelona, Humanitas, 1983, 11-84.

SÁNCHEZ GONZÁLEZ DE HERRERO, María, "De Proprietatibus Rerum, versionescastellanas", Cahiers de recherches médiévales et humanistes Journal ofmedieval and humanistic studies, 16, 2008, 349-366.

SHELL, M., "The Ring of Gyges", Mississippi Review, 17, 1/2, 1989, 21-84. SKEMER, Don, Binding Words. Textual amulets in the Middle Ages, Pennsylvania, The Pennsylvania State University Press, 2006.

STEELE, Robert, Medieval Lore. An Epitome of the science, geography, animaland plant folklore and myth of the Middle Age: being classified gleaningsfrom Encycopledia of Bartholomew Anglicus on the Properties of Things, London, E. Scott ed., 1893.

TAUSIET, María, Abracadabra Omnipotens. Magia urbana en Zaragoza en laEdad Moderna, Madrid, Siglo XXI, 2007.

The Penny Cyclopadia of the Society for the Diffusion of Useful Knowledge, Londres, 1833-1843, vol. 21.

THORNDIKE, Lynn, "The Latin Pseudo-Aristotle and Medieval Occult Science", The Journal of English and Germanic Philology, 21, 2, 1922, 229-258.

A History of magic and experimental science, New York, The Macmillan Company, 1929, 2 vols. 